\title{
Vertical and longitudinal electron density structures of equatorial E- and F-regions
}

\author{
P. S. Brahmanandam ${ }^{1,2}$, Y.-H. Chu ${ }^{2}$, K.-H. Wu ${ }^{2}$, H.-P. Hsia ${ }^{2}$, C.-L. Su ${ }^{2}$, and G. Uma ${ }^{1,2}$ \\ ${ }^{1}$ Dept. of Electronics \& Communication Engineering, K L University, Vaddeswaram 522502, India \\ ${ }^{2}$ Institute of Space Science, National Central University, Chung-Li, Taiwan
}

Received: 17 July 2009 - Revised: 17 May 2010 - Accepted: 28 December 2010 - Published: 10 January 2011

\begin{abstract}
From global soundings of ionospheric electron density made with FORMOSAT 3/COSMIC satellites for September 2006-August 2009, day-night variations in vertical and longitudinal structures of the electron densities in equatorial E- and F-regions for different seasons are investigated for the first time. The results reveal that the wavenumber- 3 and wavenumber- 4 patterns dominated the nighttime (22:00-04:00 LT) F-region longitudinal structures in solstice and in equinox seasons, respectively. In daytime (08:00-18:00 LT) F-region, the wavenumber-4 patterns governed the longitudinal structures in the September equinox and December solstice, and wavenumber-3 in March equinox and June solstice respectively. A comparison of the daytime and nighttime longitudinal electron density structures indicates that they are approximately $180^{\circ}$ out of phase with each other. It is believed that this out of phase relation is very likely the result of the opposite phase relation between daytime and nighttime nonmigrating diurnal tidal winds that modulate background E-region dynamo electric field at different places, leading to the day-night change in the locations of the equatorial plasma fountains that are responsible for the formation of the F-region longitudinal structures. Further, a good consistency between the locations of the density structures in the same seasons of the different years for both daytime and nighttime epochs has been noticed indicating that the source mechanism for these structures could be the same.
\end{abstract}

Keywords. Ionosphere (Electric fields and currents; Equatorial ionosphere)

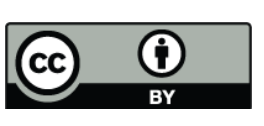

Correspondence to:

P. S. Brahmanandam

(anand.potula@gmail.com)

\section{Introduction}

Recently reported longitudinal four-wave structures in the low latitude ionospheric density distributions as observed by a number of satellite measurements have been attributed to the eastward propagating non-migrating diurnal tides with wavenumber-3 (DE3) (Sagawa et al., 2005; Immel et al., 2006; England et al., 2006a, b; Lin et al., 2007), which are believed to be originated from the convective activities in the troposphere and propagating upward (Hagan and Forbes, 2002). Owing to the wavenumber-4 longitudinal structure of DE3, when viewed in the local-time fixed reference, the longitudinal four-wave structures will be produced in the overlying ionosphere by these DE3 tidal waves at their four peaks. In an elaborative sense, the regular tidal wind system drives ionospheric plasma at dynamo layer heights $(\sim 100$ $170 \mathrm{~km})$ and pushes it against the geomagnetic field. Ions and electrons are affected differently by these winds. While the ions being massive still move essentially with the neutrals, the geomagnetic field already controls the motion of the electrons. The differential motion of ions and electrons is responsible for horizontally flowing electric currents. Moreover, charge separation generates an electric polarization field. The generated polarization fields, eventually, will be connected via magnetic field lines to the equatorial Fregion where they enhance the accompanying $\boldsymbol{E} \times \boldsymbol{B}$ vertical drifts to produce equatorial ionization anomaly peaks. When viewed at one fixed local time from satellite, this feature exhibits as a four-peak structure, which was noted as wavenumber- 4 component in the overlying F-region by the above workers. However, the aforementioned studies (for example, Immel et al., 2006; England et al., 2006a, b; and Lin et al., 2007) pertained to either vernal or autumnal equinox months in one year, during these periods the DE3 is characterized with significantly enhanced amplitude (Forbes et al., 2008). Hence, it was generally conceived that the eastward propagating non-migrating diurnal tide could play a

Published by Copernicus Publications on behalf of the European Geosciences Union. 
role in the four-wave structures in electron densities via the E-region dynamo mechanism. Immediately questions will be raised about the relative importance of other tidal waves (for example DE2, SE3, SE2 and DW1, DW2 etc.) particularly when the DE3 tidal wave significance is less i.e., during winter solstice (Forbes et al., 2008). Based on their latitudinal extent, vertical wavelength, hemispheric symmetry and wave amplitude, the relative importance of tidal waves in generating electric fields appears to be DE3, DE2, SW4 and SW3 (in the order of importance) respectively (Forbes et al., 2008) which means during the absence of DE3, other tidal waves should play an effective role in generating electric fields, which may eventually govern the wave- 3 , wave2 and wave-5 longitudinal ionospheric structures. To verify these aspects, studies on seasonal variations of ionospheric structures with advanced data analysis methods will be carried out as it is believed that these may provide clues on the possible role of tidal winds in the modulation of electric fields in order to produce longitudinal structures in the overlying ionosphere. As a matter of fact, both observational and modeling studies, though very few, on the seasonal variations in longitudinal ionospheric structures have been documented particularly after the Immel et al. (2006) report, who postulated for the first time that the fate of longitudinal structures would be dictated by the upward propagating tidal waves. For instance, after careful inspection of TEC data measured by the TOPEX/Poseidon altimeter for more than 13 years (between August 1992 and October 2005), Scherliess et al. (2008) found that the wavenumber-4 longitudinal structure is observed during equinox in daytime as well as in nighttime and is prominent only during nighttime in June Solstice, while wavenumber-3 longitudinal structure is observed during December Solstice. Ren et al. (2008) analyzed ion density and electron temperature measured by the Defense Meteorological Satellite Program (DMSP) F13 Satellite at the local time around 1745 for the period 1995-2005 and showed that the longitudinal variations in the electron temperature and total ion density in the equatorial topside ionosphere exhibit salient seasonal dependence, in which the wavenumber-4 longitudinal structures prevail in equinox and two and three peaks structures are, respectively, dominant in December and June solstice seasons. Ren et al. (2008) have argued that the wavenumber-4 longitudinal structures during equinox epochs may be due to DE3, while three and two wave structures during June and December solstice induced by both the longitudinal variation of geomagnetic declination and DE3. Further, series of simulations of the National Center for Atmospheric Research (NCAR) Thermosphereionosphere-mesosphere general circulation model (TIMEGCM) indicated that the wavenumber-4 longitudinal structures in the equinox nighttime equatorial ionization anomaly (EIA) can be explained by the effects of an eastward propagating non-migrating diurnal tide with wavenumber-3 (DE3) (Hagan et al., 2007). Nevertheless, these studies focused only on two-dimensional perspectives of longitudinal struc- tures. Questions immediately arise as to what the vertical structure of the longitudinal electron density pattern is. How does it change with season and from day to night? It will definitely be an interesting study to verify the vertical structure of the longitudinal electron densities in three-dimensional perspectives in different seasons. To attain these goals, the measurements of global electron density profiles with sufficiently high resolutions in space and time for a long period of time are required. With the aid of low orbit satellites performing GPS radio occultation observations, it has been shown possible to obtain global soundings of the electron density profiles in the height range from lower E-region to topside ionosphere with vertical resolution of about $1 \mathrm{~km}$ (Schreiner et al., 2007; Yang et al., 2009).

An attempt is made in this article to employ the globally GPS-retrieved electron densities for more than three years span of time made with the FORMOSAT-3/COSMIC satellite system, which consists of 6 small satellites deployed at $800 \mathrm{~km}$ altitude to form a constellation with orbit planes of equal separation, to investigate the vertical structure of the longitudinal electron density pattern in equatorial E- and Fregions. Note that the electron densities in the ensuing sections are shown in different seasons (the March and September equinoxes and the June and December solstices, respectively) in a year and each season contains a 3-month period. It is found that, in addition to seasonal variation, there are significantly day-night changes in the vertical and longitudinal electron density structures. This article is organized as follows. In Sect. 2, data analysis and methodology that we adopted in this study will be presented. The salient results of this study are given in Sect. 3. The plausible physical mechanisms responsible for these features are discussed in Sect. 4 and summary and conclusions are given in Sect. 5 .

\section{Data analysis and methodology}

Six-micro satellites constellation FORMOSAT-3/COSMIC (F3/C in short) was lunched successfully at 01:40 UTC on 15 April 2006 into a circular low earth orbit at an inclination of $72^{\circ}$. The ionospheric electron density profiles employed in this study were retrieved by the $\mathrm{F} 3 / \mathrm{C}$ satellites in terms of radio occultation inversion technique for period from September 2006 to August 2008. The core of the radio occultation technique is to perform the transformation from the measured excess phase of the GPS signal to the ionospheric electron density over the tangent point of the GPS ray (Schreiner et al., 1999). In general, 1500-2200 soundings of the electron density in the height region from $100 \mathrm{~km}$ to $800 \mathrm{~km}$, which are distributed approximately uniformly around the globe, can be collected in $24 \mathrm{~h}$ by the F3/C satellites. For complete details of the GPS radio occultation technique for ionospheric electron density inversion, the reader is referred to Schreiner et al. (1999). 
Daytime (08-18 LT)

Sep 2007 - Nov 2007

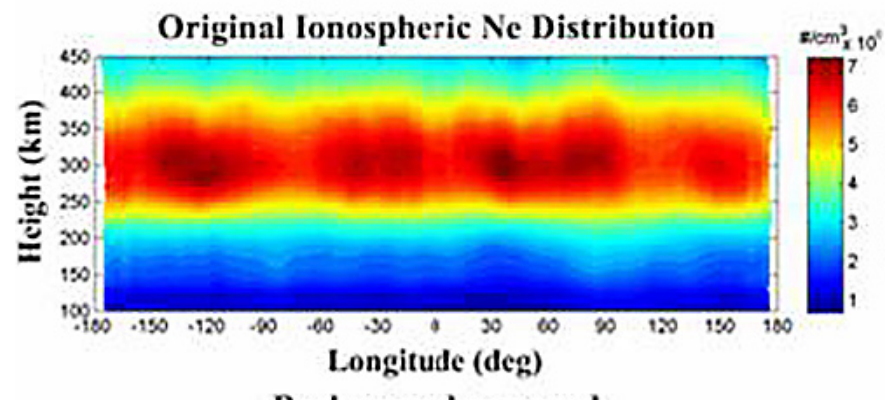

Background-removed

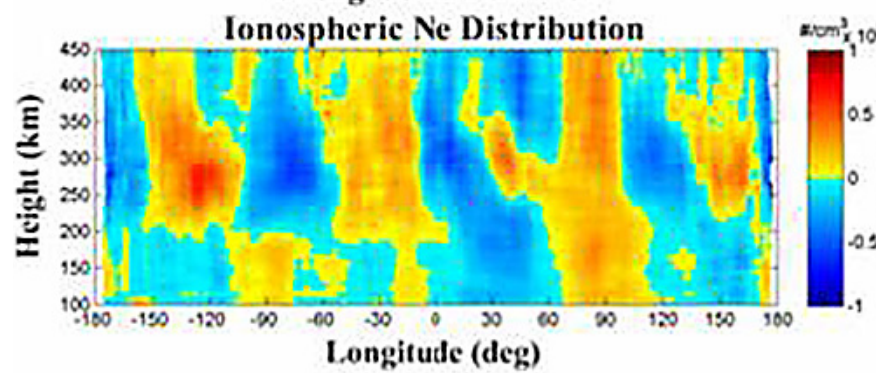

Nighttime (22-04 LT)

Sep 2007 - Nov 2007

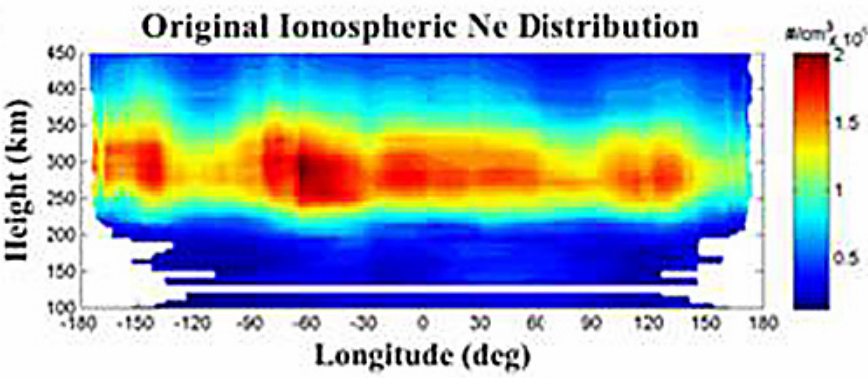

Background-remored

Ionospheric Ne Distribution

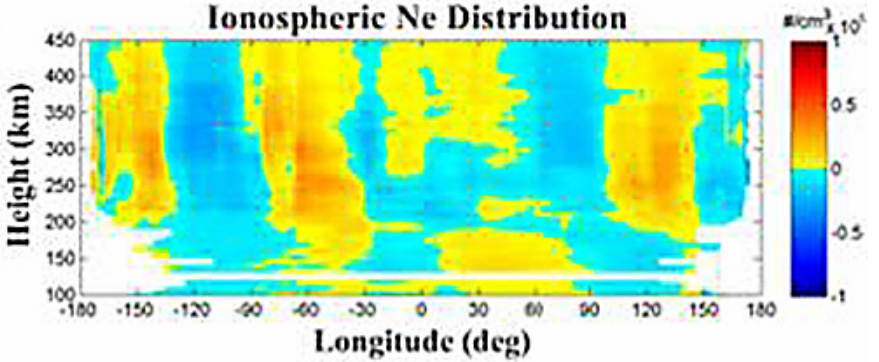

Fig. 1. Example of height versus longitude distributions of original (upper panels) and background-removed (lower panels) ionopsheric electron densities along the equator for the period September-November 2007, in which daytime (08:00-18:00 LT) (left panels) and nighttime (22:00-04:00 LT) (right panels) averages were, respectively, demonstrated for comparison.

A number of factors, such as thermal noise fluctuations of the received signals, sharp gradients of the ionospheric refractive index in vertical and horizontal directions, system bias of the excess phase, inaccurate position of the satellites, and so on, may influence the accuracy and precision of the retrieved bending angle in terms of radio occultation technique, causing physically erroneous inversion results (Schreiner et al., 2007). In addition, the presence of plasma irregularities in the GPS ray path may cause significant fluctuations of the retrieved electron density profile, giving rise to large uncertainty of the estimation and impairment of the data reliability (Yang et al., 2009). In this study, we use the criteria of data quality control developed by Yang et al. (2009) to remove questionable and unreliable data from original data set. Moreover, the retrieved electron densities for the conditions of geomagnetic Kp index greater than 3 are also not included in the data analysis to limit effects from geomagnetic disturbances.

\section{Results}

In order to underscore the longitudinal patterns of the equatorial electron density variations in different seasons and heights, we employ a three order polynomial to best fit to the longitudinal electron density variations at different heights. The vertical structures of the background-removed longitudinal variation patterns can thus be obtained after the fitted polynomials are subtracted from the original longitudinal variations, which are considered to be the background values along the equator. Figure 1 presents examples of height versus longitude distributions of original (upper panels) and background-removed (lower panels) ionopsheric electron densities for the period September 2007-November 2007, in which daytime average (08:00-18:00 LT) (left panels) and nighttime average (22:00-04:00 LT) (right panels) electron density distributions along the geomagnetic equator are, respectively, demonstrated for comparison. Note that the GPS-retrieved electron densities in the latitudinal region within $0 \pm 5^{\circ}$ with respect to the geomagnetic equator were employed to construct Fig. 1 and the remaining figures in this article. As shown, a one-to-one correspondence between the peaks (or troughs) of the background-removed electron density fluctuations and those of the original electron density variations is seen, especially for the data around peak electron density height. It is obvious that the background removal procedure can indeed highlight the signatures of the longitudinal electron density variations with relatively small amplitudes compared to the background values.

A careful observation of Fig. 2, in which left (right) panels show daytime (nighttime) height distributions of the longitudinal electron density variations along the geomagnetic equator for September equinox (September, October and November) in 2006 (top panels), 2007 (middle panels), and 


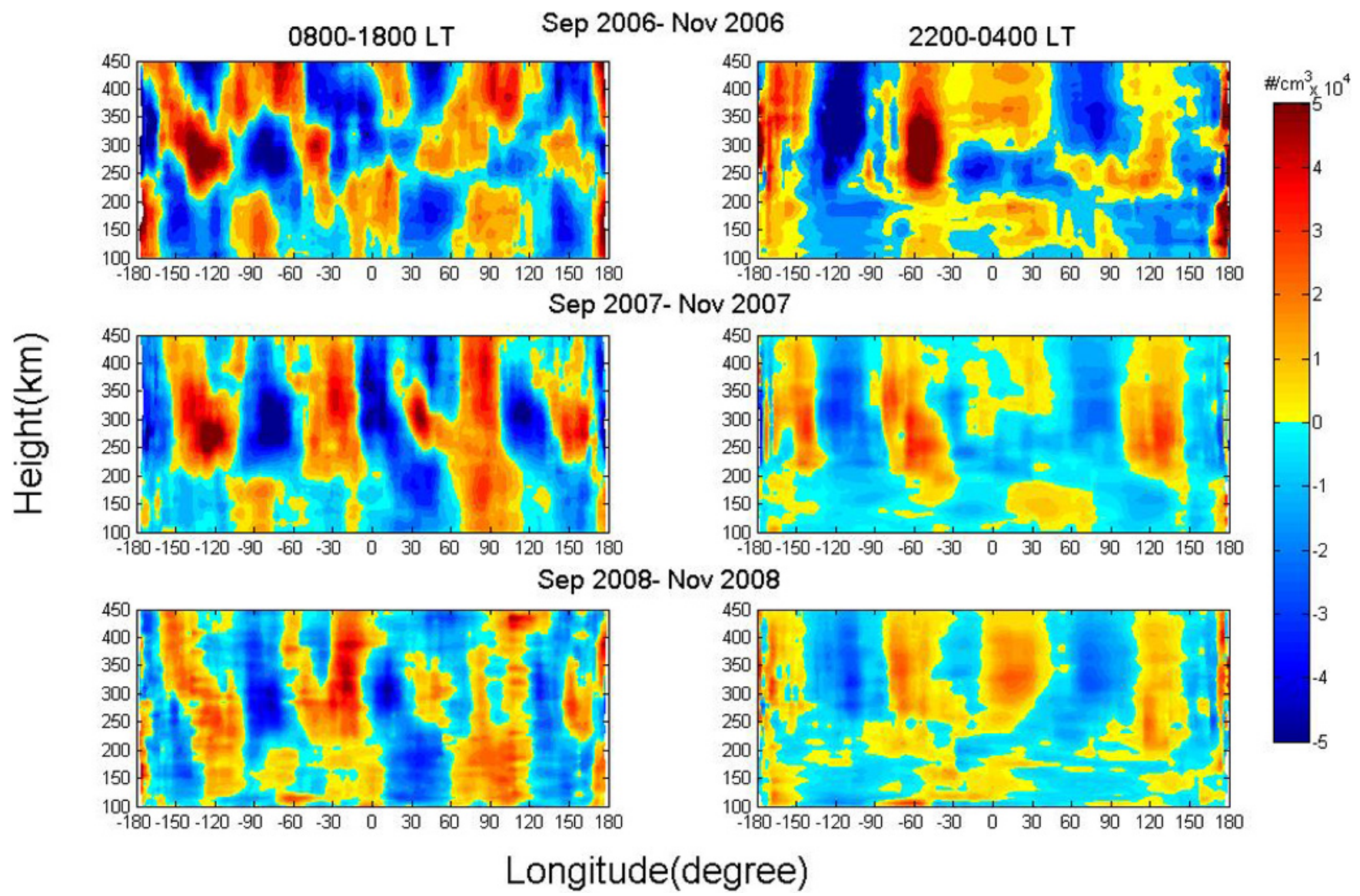

Fig. 2. Longitude versus altitude electron densities (residuals) during September equinox 2006 (upper panels), 2007 (middle panels), and 2008 (bottom panels) for both daytime (08:00-18:00 LT) and nighttime (22:00-04:00 LT).

2008 (bottom panels) respectively, revealed that the fourwave structures at $\sim 160^{\circ} \mathrm{W}, \sim 60^{\circ} \mathrm{W}, \sim 0^{\circ} \mathrm{E}$, and $\sim 120^{\circ} \mathrm{E}$ prevailed during nighttime F-region from around $200 \mathrm{~km}$ to topside ionosphere during 2006. Another noticeable finding from this figure is that the locations of four peaks during nighttime in the September equinox of 2006 have maintained pretty well consistency with their counterpart nighttime fourpeaks in September equinox of 2007 and 2008. This consistency behavior in the locations of four-peaks in longitudinal electron densities is not only implying the source mechanism for these structures is the same and it occurred repeatedly during that particular season so as to produce the four-wave longitudinal structures. It is worthwhile to mention here that the DE3 tidal wave has the capability to produce four-wave structures as mentioned in the introduction of this article and it is known to experience a clear seasonal variation in terms of its amplitude and phase (Oberheide et al., 2006). On the other hand, the daytime longitudinal structures during September equinox of 2006 is also showing four-wave structures at $\sim 150^{\circ} \mathrm{W}, \sim 0^{\circ} \mathrm{E}, \sim 90^{\circ} \mathrm{E}$, and $\sim 150^{\circ} \mathrm{E}$, while September equinox of 2007 is also characterized with fourwave structures that located at $\sim 150^{\circ} \mathrm{W}, \sim 30^{\circ} \mathrm{W}, \sim 90^{\circ} \mathrm{E}$, and $\sim 150^{\circ} \mathrm{E}$ and the four-wave structure can also be noticed during the September equinox of 2008 at $\sim 150^{\circ} \mathrm{W}$, $\sim 20^{\circ} \mathrm{W}, \sim 100^{\circ} \mathrm{E}$ with another weak structure at $\sim 160^{\circ} \mathrm{E}$ longitude. Further, by comparing both the daytime and nighttime longitudinal density structures during 2006, 2007 and 2008 , one can find an interesting relationship that the $180^{\circ}$ out of phase between their locations. Figure 3 depicts the longitudinal density structures during daytime (nighttime) in the left (right) panels of top, middle, and bottom panels for December solstices (December, January, and February) of 2006, 2007, and 2008. On contrary to the density structures in September equinox of 2006, 2007 and 2008, only three-wave longitudinal structures are present in December solstices and the locations of nighttime structures are found to be at $\sim 170^{\circ} \mathrm{W}, \sim 20-40^{\circ} \mathrm{W}, \sim 150^{\circ} \mathrm{E}$ in $2006, \sim 170^{\circ} \mathrm{W}$, $20-40^{\circ} \mathrm{W}, \sim 120-150^{\circ} \mathrm{E}$ in 2007 , and $\sim 170^{\circ} \mathrm{W}, 20-40^{\circ} \mathrm{W}$, $130-150^{\circ} \mathrm{E}$ in 2008 , respectively. Though the daytime longitudinal structures are showing relatively irregular behaviour in 2006 and 2007, a close perusal of density structures during winter season of 2008 it is possible to know the exact locations of density structures in this season during different years. For instance, one can find a four-wave structure 


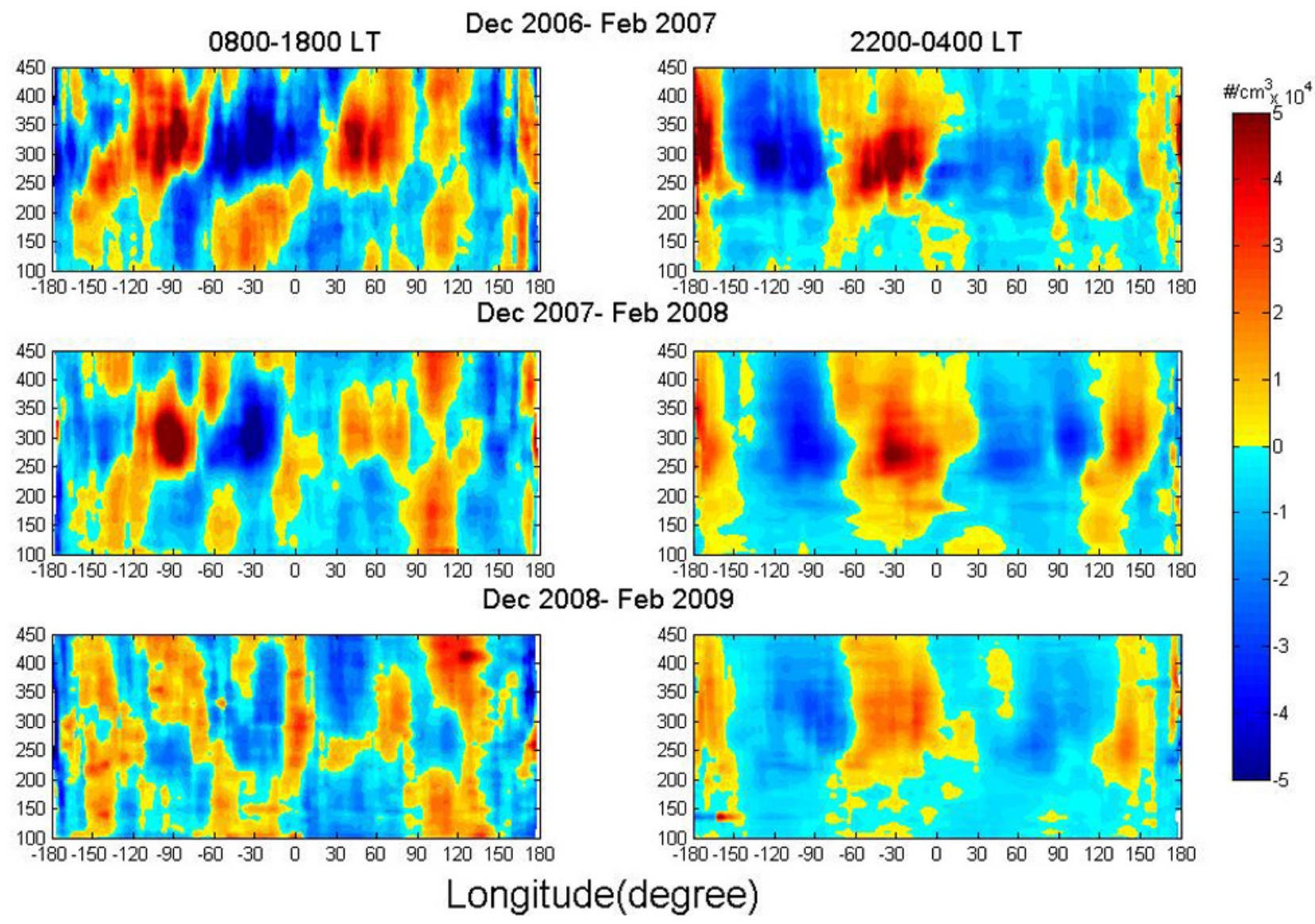

Fig. 3. Same as Fig. 2 but for December solstice in 2006, 2007 and 2008.

and the average locations of this structure is found to be at $\sim 140-150^{\circ} \mathrm{W}, \sim 90-100^{\circ} \mathrm{W}, 40-60^{\circ} \mathrm{E}, 90-120^{\circ} \mathrm{E}$ in 2006 , $\sim 140^{\circ} \mathrm{W}, \sim 90^{\circ} \mathrm{W}, 0^{\circ} \mathrm{E}, 90 \sim 120^{\circ} \mathrm{E}$ in 2007 and $\sim 150^{\circ} \mathrm{W}$, $\sim 90^{\circ} \mathrm{W}, \sim 0^{\circ} \mathrm{E}, 90-120^{\circ} \mathrm{E}$ in 2008 . It is obvious that the structure at $140-150^{\circ} \mathrm{W}$ longitude during winter season of 2006 is seemed to merge with the adjacent one, that is located at $\sim 90-100^{\circ} \mathrm{W}$, and the structure at $40-60^{\circ} \mathrm{E}$ is not present either in 2007 or 2008 . The out of phase relation between daytime and nighttime structures, particularly in the Fregion, is also prevailed during this season in the same lines with the September equinox season.

Figure 4 shows the longitudinal density structures for daytime and nighttime in March equinox (March, April, and May) of 2007, 2008 and 2009. A striking feature from this figure that a clear four-wave structure during nighttime is found in three years starting from $\sim 250 \mathrm{~km}$ to topside ionosphere and their respective locations are $\sim 150^{\circ} \mathrm{W}$, $\sim 90^{\circ} \mathrm{W}, \sim 20^{\circ} \mathrm{E}, \sim 110-120^{\circ} \mathrm{E}$ in $2007, \sim 150^{\circ} \mathrm{W}, \sim 90^{\circ} \mathrm{W}$, $\sim 20^{\circ} \mathrm{E}, \sim 130^{\circ} \mathrm{E}$ in 2008 , and $\sim 140^{\circ} \mathrm{W}, \sim 90^{\circ} \mathrm{W}, \sim 20^{\circ} \mathrm{E}$, $\sim 120^{\circ} \mathrm{E}$. On the other hand, the daytime densities are characterized with three-wave structures at $\sim 120^{\circ} \mathrm{W}, \sim 30^{\circ} \mathrm{W}$, $\sim 80-110^{\circ} \mathrm{E}$ in year 2007 March equinox season while densities during 2008 equinox season seem to have also characterized with three-wave structures from $200 \mathrm{~km}$ to topside iono- sphere at $\sim 120^{\circ} \mathrm{W}, \sim 60^{\circ} \mathrm{W}, \sim 80-110^{\circ} \mathrm{E}$ and the density structures during 2009 are located at $\sim 120^{\circ} \mathrm{W}, 30^{\circ} \mathrm{W}$, and $\sim 80-110^{\circ}$ E. Further, the out of phase relation between daytime and nighttime structures in 2007, 2008 and 2009 is also existed particularly in the F-region. Figure 5 shows the longitudinal density structures in June solstice (June, July, and August) in 2007, 2008, and 2009 for both day and nighttime periods. Though a clear three-wave structure is dominated in the daytime as well as in nighttime during June solstice season in 2007, 2008 and 2009, the nighttime three-wave structures are present only starting from around $250 \mathrm{~km}$ altitude to topside ionosphere during 2007 and 2008 and the average locations of these structures during nighttime and daytime are found at between $90 \sim 150^{\circ} \mathrm{W}, \sim 30^{\circ} \mathrm{E}, \sim 80-120^{\circ} \mathrm{E}$ and $\sim 90-150^{\circ} \mathrm{W}, \sim 0^{\circ} \mathrm{E}, \sim 90-1210^{\circ} \mathrm{E}$, respectively. Another interesting observation during this season is that, contrary to other seasons shown before, the $180^{\circ}$ out of phase relation between day and nighttime structures did not observe particularly between $90^{\circ}$ and $150^{\circ} \mathrm{W}$ longitude zone. The plausible physical process responsible for the in-phase relation between daytime and nighttime longitudinal structures during December solstice and the anti-phase during the rest of seasons is discussed in the ensuing section. 


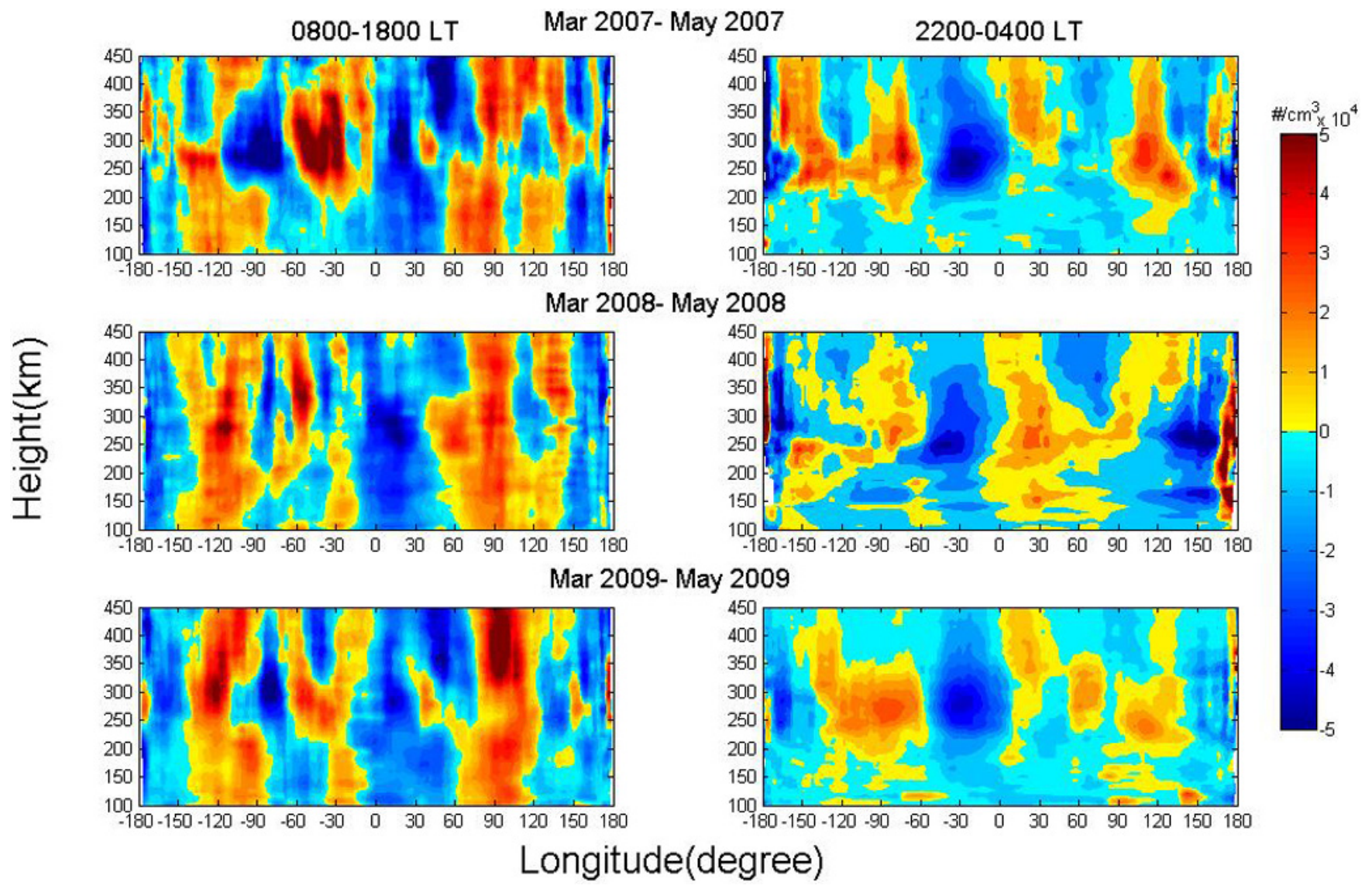

Fig. 4. Same as Fig. 2 but for March equinox in 2007, 2008 and 2009.

Although the global patterns of the longitudinal F-region electron density have been extensively investigated, longitudinal variations of the vertical structures of electron density in equatorial E- and F-regions simultaneously have not been well documented in literature and their day/night and seasonal variations are also not fully explored. More importantly, the vertical structures are very essential to understand the physical mechanism that is responsible for these variations. Keeping above in mind, we also present for the first time the day/night and seasonal variations of vertical electron density structures of equatorial E- and F-regions simultaneously during different seasons in three continuous years and discussed the observational results in the following lines concisely. As shown in Figs. 2 to 5, the daytime longitudinal structures are almost extended vertically throughout the E-region, while the nighttime structures are relatively weak and disorganized compared to the daytime structures. Overall, as the daytime longitudinal structures in E-region are concerned, the wavenumber-4 patterns are discernible in December solstice only. For the nighttime structures, relatively weak wavenumber-3 patterns are present in the December solstice, and wavenumber-4 patterns appear in the March equinox.

\section{Discussion}

The global soundings of the radio-occultated electron density retrieved by the F3/C satellites allow for the first time a detailed analysis of the day-night and seasonal variations in the vertical and longitudinal electron density structures in equatorial E- and F-regions. The present results suggest that in nighttime F-region above $250 \mathrm{~km}$ the longitudinal wavenumber-4 patterns prevail in equinox and the wavenumber-3 structures dominate the longitudinal electron density variations in boreal solstice. The appearance of the nighttime F-region wavenumber-4 structures in equinox presented here is generally consistent with that obtained by previous investigations (England et al., 2006a, b; Immel et al., 2006; Lin et al., 2007; Ren et al., 2008; Scherliess et al., 2008). However, appreciable differences between present and other experimental results in the daynight/seasonal variations in the longitudinal structures are also found. For example, Ren et al. (2008) observed the manifest wavenumber-2 structures in December solstice with peaks located at $40^{\circ} \mathrm{W}$ and $120^{\circ} \mathrm{E}$. However, the nighttime data presented in Fig. 4 show that, in addition to these two peaks, a third peak at around $170^{\circ} \mathrm{W}$ is occurred consistently 


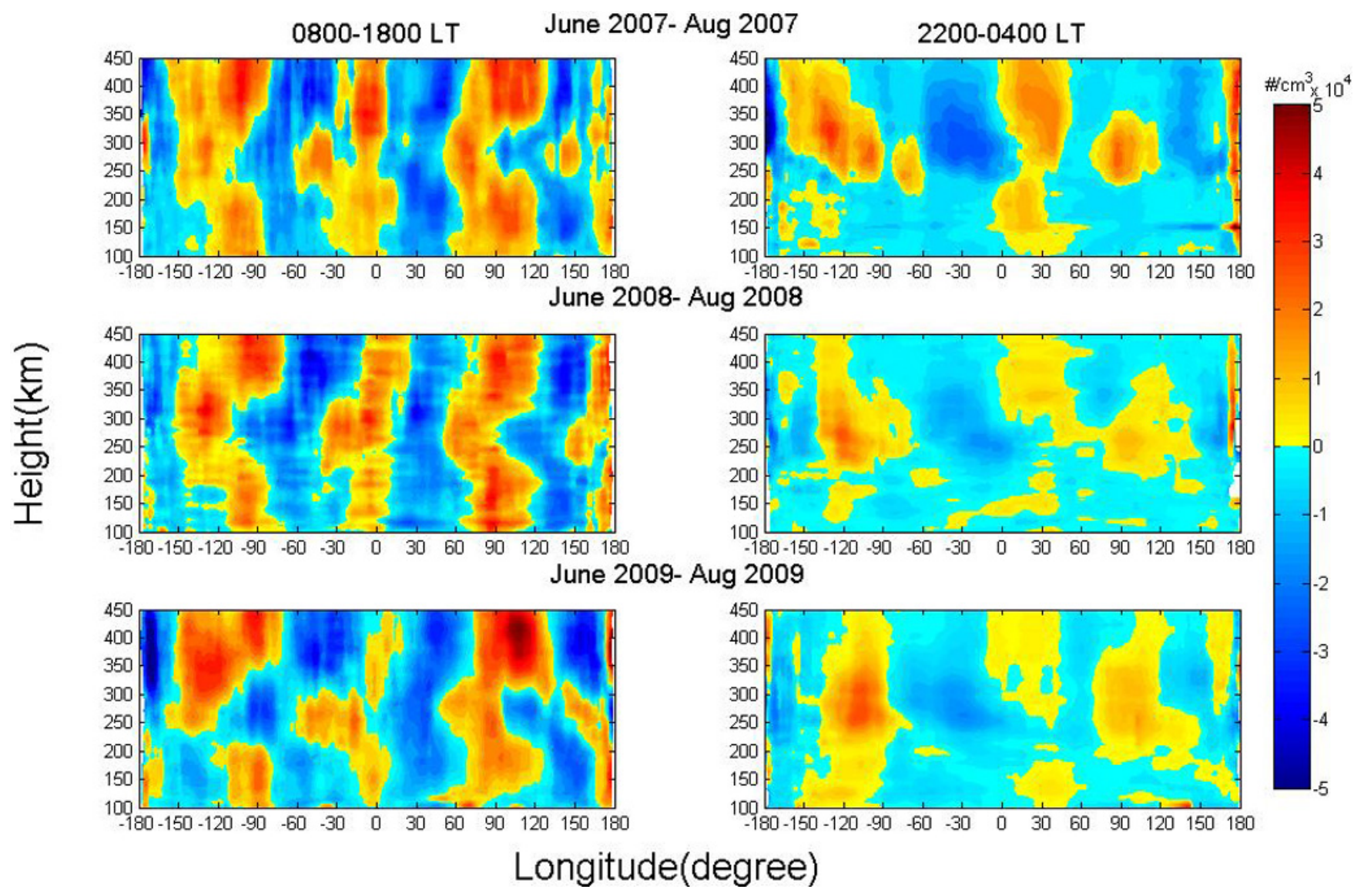

Fig. 5. Same as Fig. 2 but for June solstice in 2007, 2008, and 2009.

during December solstice of 2006, 2007, and 2008. Moreover, Wan et al. (2008) reported that the wavenumber-4 patterns are weak in nighttime December solstice and intense in daytime June solstice and October equinox. However, our results show that the wavenumber- 3 patterns are dominant in nighttime December solstice, but also prevalent in day and nighttime F-region in June solstices. The causes of the disagreements between present and other experimental results on the seasonal and day-night variations in the longitudinal patterns in E- and F-regions are not clear, and more data from other sources are needed to investigate these disagreements.

In general, an approximately $180^{\circ}$ out of phase relation between the daytime and nighttime longitudinal electron density structures is found in most part of the equatorial F-region above $200 \mathrm{~km}$. This out of phase relation is also seen in the diurnal variation of the longitudinal TEC distributions in equatorial region (Wan et al., 2008), equatorial $\boldsymbol{E} \times \boldsymbol{B}$ drifts that measured with the ROCSAT-1 satellite (Kil et al., 2008), and equatorial $\boldsymbol{E} \times \boldsymbol{B}$ drifts that simulated with a theoretical ionospheric dynamo model (Ren et al., 2010). It is generally believed that the nonmigrating tidal waves play a critical role in the generation of the longitudinal electron density patterns in equatorial E- and F-region, which are excited in tropical troposphere by latent heat release of water vapor condensation (Hagan et al., 2007; Immel et al., 2006; Forbes et al., 2008). Specifically, the nonmigrating eastward wavenumber3 diurnal tide (DE3) is thought to be responsible for the longitudinal four peak structures in F-region, which modulates the off-equator background E-region dynamo electric fields that transmit upward into equatorial F-region along the magnetic field lines to create the F-region longitudinal electron density structures through $\boldsymbol{E} \times \boldsymbol{B}$ effect (Sagawa et al., 2005; Immel et al., 2006; England et al., 2006a, b; Hagan et al., 2007; Kil et al., 2007; Ren et al., 2008). It is evident that, when they are viewed in different local time reference frames with $12 \mathrm{~h}$ separation, the longitudinal variation in the amplitude of a nonmigrating diurnal tide in daytime is expected to be opposite in phase to that in nighttime (Kato, 1989). As a result, the polarized electric field caused by the convergence of the daytime poleward tidal wind-induced Pedersen current in E-region will be out of phase with that induced by the nighttime diurnal tidal wind. If the eastward polarized electric fields are larger than the nighttime westward background dynamo electric field, the ionizations in equatorial F-region are able to be uplifted by the $\boldsymbol{E} \times \boldsymbol{B}$ drift effect and the electron density in the lifting region are expected to be larger than 
that in neighboring region (Kil et al., 2007). Consequently, the out of phase relation between the daytime and nighttime F-region longitudinal structures can be explained.

It is evident from the bottom panel of Fig. 5 that, except for their out of phase relation, the daytime longitudinal structure in longitudinal region $90^{\circ} \mathrm{W}-150^{\circ} \mathrm{W}$ for June solstice is nearly in phase with that for the nighttime structure. Note that the longitudinal wavenumber-3 patterns prevailed in June solstice, which can be induced by eastward nonmigrating diurnal tide DE2 and semidiurnal tide SE1 (Kato, 1989; Forbes et al., 2008). Although TIMED/SABER measurements show that in average the amplitudes of SE1 are approximately 2 times smaller than those of DE2 in equatorial E-region at $116 \mathrm{~km}$, the former may occur intermittently at significant amplitude (Forbes et al., 2008). It follows that, because the in phase (out of phase) relation between daytime and nighttime longitudinal wavenumber-3 structures is expected for SE1 (DE2) viewed in constant local time reference frames with $12 \mathrm{~h}$ difference, the observed in phase relation seems to suggest the dominance of SE1 over DE2 in June solstice in the longitudinal zone around $90^{\circ} \mathrm{W}-150^{\circ} \mathrm{W}$.

\section{Conclusions}

On the whole, the day-night and seasonal variations in the vertical and longitudinal electron density structures are clearly revealed. In nighttime, the wavenumber-4 structures prevail in equinox seasons and the wavenumber-3 patterns are the dominant structures in solstice seasons in F-region although the nighttime structures in E-region below $200 \mathrm{~km}$ were relatively disorganized and irregular. In daytime, on the whole, the wavenumber- 3 and 4 patterns govern the longitudinal structures in F-region in the March equinox, and June solstice and in September equinox and December solstice, respectively. It is also found that the longitudinal variations in daytime electron density have a tendency to be $180^{\circ}$ out of phase with those in nighttime electron density throughout F-region. This feature provides supporting evidence that the eastward nonmigrating diurnal tides DE2 and DE3 are very likely the main causes of the longitudinal wavenumber-3 and 4 structures in equatorial F-region.

Electrodynamics related to the DE3 tide investigated by Jin et al. (2008) using a numerical electrodynamical model for September equinox conditions and have reached to a conclusion that the DE3 tide could able to generate perturbations in the F-region electric fields which produce eventually longitudinal four-wave structures. Though the scientific fraternity has come to a consensus on the role of DE3 in the generation of wavenumber-4 structures via dynamo mechanism and subsequent phenomena particularly during equinox epochs, the absolute and relative efficiencies of other tidal waves that we discussed in the present article in the modulation of dynamo electric fields in order to produce the corresponding longitudinal structures in the F-region iono- sphere yet to be determined which may be realized by using a realistic and tested dynamo model studies such as Hagan et al. (2007) and Jin et al. (2008) and through exhaustive seasonal longitudinal studies of ionospheric structures using available satellite measurements as well as future missions.

Acknowledgements. This work was supported by the National Space Program Office (NSPO) of the Republic of China under the grants 97NSPO (B)-SP-FA07-02 (A).

Topical Editor M. Pinnock thanks W. Wan and another anonymous referee for their help in evaluating this paper.

\section{References}

England, S. L., Immel, T. J., Sagawa, E., Henderson, S. B., Hagan, M. E., Mende, S. B., Frey, H. U., Swenson, C. M., and Paxton, L. J.: The effects of atmospheric tides on the morphology of the quiet-time, post-sunset equatorial ionospheric anomaly, J. Geophys. Res., 111, A10S19, doi:10.1029/2006JA011795, 2006 a.

England, S. L., Maus, S., Immel, T. J., and Mende, S. B.: Longitudinal variation of the E-region electric fields caused by atmospheric tides, Geophys. Res. Lett., 33, L21105, doi:10.1029/2006G1027465, 2006b.

Forbes, J. M., Zhang, X., Palo, S., Russell, C., Mertens, J., and Mlynczak, M.: Tidal variability in the ionospheric dynamo region, J. Geophys. Res., 113, A02310, doi:10.1029/2007JA012737, 2008.

Hagan, M. E. and Forbes, J. M.: Migrating and nonmigrating semi-diurnal tides in the upper atmosphere excited by tropospheric latent heat release, J. Geophys. Res., 107(D24), 4754, doi:10.1029/2001JD001236, 2002.

Hagan, M. E., Maute, A., Roble, R. G., Richmond, A. D., Immel, T. J., and England, S. L.: Connections between deep tropical clouds and the Earth's ionosphere, Geophys. Res. Lett., 34, L20109, doi:10.1029/2007GL030142, 2007.

Immel, T. J., Sagawa, E., England, S. L., Henderson, S. B., Hagan, M. E., Mende, S. B., Frey, H. U., Swenson, C. M., and Paxton, L. J.: Control of equatorial ionospheric morphology by atmospheric tides, Geophys. Res. Lett., 33, L15108, doi:10.1029/2006GL026161, 2006.

Jin, H., Miyoshi, Y., Fujiwara, H., and Shinagawa, H.: Electrodynamics of the formation of ionospheric wavenumber4 longitudinal structure, J. Geophys. Res., 113, A09307, doi:10.1029/2008JA013301, 2008.

Kato, S.: Non-migrating tides, J. Atmos. Terr. Phys., 51, 673-682, 1989.

Kil, H., Oh, S.-J., Kelley, M. C., Paxton, L. J., England, S. L., Talaat, E., Min, K.-W., and Su, S.-Y.: Longitudinal structure of the vertical ExB drift and ion density seen from ROCSAT-1, Geophys. Res. Lett., 34, L14110, doi:10.1029/2007GL030018, 2007.

Kil, H., Talaat, E. R., Oh, S.-J., Paxton, L. J., England, S. L., and Su, S.-Y.: Wave structures of the plasma density and vertical $\mathrm{E} \mathrm{x}$ B drift in low-latitude F-region, J. Geophys. Res., 113, A09312, doi:10.1029/2008JA013106, 2008.

Lin, C. H., Wang, W., Hagan, M. E., Hsiao, C. C., Immel, T. J., Hsu, M. L., Liu, J. Y., Paxton, L. J., Fang, T. W., and Liu, C. H.: Plausible effect of atmospheric tides on the equatorial ionosphere observed by the FORMOSAT-3/COSMIC: Three-dimensional 
electron density structures, Geophys. Res. Lett., 34, L11112, doi:10.1029/2007GL029265, 2007.

Ren, Z., Wan, W., Liu, L., Zhao, B., Wei, Y., Yue, X., and Heelis, R. A.: Longitudinal variations of electron temperature and total ion density in the sunset equatorial topside ionosphere, Geophys. Res. Lett., 35, L05108, doi:10.1029/2007GL032998, 2008.

Ren, Z., Wan, W., Xiong, J., and Liu, L.: Simulated wave number 4 structure in equatorial F-region vertical plasma drifts, J. Geophys. Res., 115, A05301, doi:10.1029/2009JA014746, 2010.

Sagawa, E., Immel, T. J., Frey, H. U., and Mende, S. B.: Longitudinal structure of the equatorial anomaly in the nighttime ionosphere observed by IMAGE/FUV, J. Geophys. Res., 110, A11302, doi:10.1029/2004JA010848, 2005.

Scherliess, L., Thompson, D. C., and Schunk, R. W.: Longitudinal variability of low-latitude total electron content: Tidal influences, J. Geophys. Res., 113, A01311, doi:10.1029/2007JA012480, 2008.
Schreiner, W. S., Sokolovskiy, S. V., Rocken, C., and Hunt, D. C.: Analysis and validation of GPS/MET radio occultation data in the ionosphere, Radio Sci., 34, 949-966, 1999.

Schreiner, W., Rocken, C., Sokolovskiy, S., Syndergaard, S., and Hunt, D. C.: Estimates of the precision of GPS radio occultations from the COSMIC/FORMOSAT-3 mission, Geophys. Res. Lett., 34, L04808, doi:10.1029/2006GL027557, 2007.

Wan, W., Liu, L., Pi, X., Zhang, M.-L., Ning, B., Xiong, J., and Ding, F.: Wavenumber-4 patterns of the total electron content over the low latitude ionosphere, Geophys. Res. Lett., 35, L12104, doi:10.1029/2008GL033755, 2008.

Yang, K. F., Chu, Y. H., Su, C. L., Ko, H. T., and Wang, C. Y.: An examination of FORMOSAT- 3/COSMIC F peak measurements: Data Quality Criteria and Comparisons with the IRI model, Terr. Atmos. Ocean. Sci., 20(1), 193-206, 2009. 